\title{
The Relationship between Critical Thinking Ability and Reading Strategies used by Iranian EFL Learners
}

\author{
Esmaeel Nour Mohammadi ${ }^{1}$, Farrokhlagha Heidari ${ }^{1} \&$ Nasrin Dehghan Niry ${ }^{1}$ \\ ${ }^{1}$ Department of English Language and Literature, University of Sistan and Baluchestan, Zahedan, Iran \\ Correspondence: Nasrin Dehghan Niry, No. 133, K Block, Negin Residential Complex, Mahdasht, Alborz \\ Province, Iran. Tel: 98-091-2563-2981. E-mail: nasrindehghan78@yahoo.com
}

Received: July 11, 2012 Accepted: August 10, 2012 Online Published: August 23, 2012

doi:10.5539/elt.v5n10p192 URL: http://dx.doi.org/10.5539/elt.v5n10p192

\begin{abstract}
The current empirical study aimed to identify those categories of reading strategies (cognitive, meta-cognitive, and compensation) that are mostly used by Iranian EFL learners, and investigate if there is any significant relationship between critical thinking ability and reading strategies used by these learners. It also pursued if there is any significant difference between critical thinking ability of male and female learners. Seventy five Iranian EFL senior students (35 males and 40 females) majoring in English Literature and EnglishTranslation at the University of Sistan and Baluchestan in Iran participated in this study. Based on the purposes of the study, two questionnaires were administered to the participants: a critical thinking questionnaire and a reading strategy questionnaire. Results of the study showed that the most frequently used reading strategy was meta-cognitive strategy. Statistical analyses revealed a low positive significant correlation between learners' critical thinking ability and their overall use of reading strategies. The participants' critical thinking ability also correlated positively with their use of each one of cognitive, meta-cognitive, and compensation strategies. An independent-samples $t$-test was employed to examine the difference between critical thinking ability of males and females and the result revealed a significant difference between male and female learners in their critical thinking; males' critical thinking ability was higher than that of females.
\end{abstract}

Keywords: critical thinking, reading strategies, Iranian EFL learners

\section{Introduction}

Recent research on reading has shown that reading is a complex cognitive activity that is indispensable for adequate functioning and for obtaining information in contemporary society (Shang, 2010). Chamot (2004) defines reading skill as a process that involves the activation of relevant knowledge and language skills to get information across from one individual to another. Chastain (1988, p. 216) also argues that "reading is the activation of relevant knowledge and related language skills in order to accomplish an exchange of information from one person to another".

Among the four skills of learning English, reading ability is the most important skill and it has received much more attention than others in EFL environments. This skill is highly valued by students and teachers alike (Richards \& Renandya, 2000). In Iran, where access to English native speakers for talking is limited, reading is considered as an essential skill to develop English as a foreign language. It can be considered as an important activity in any language classroom, not only as a source of information and a pleasurable activity, but also as a means of improving one's knowledge of the language. According to Singhal (2001), recently many researchers, teachers and teacher trainers of foreign languages aimed to identify the processes and strategies involved in reading skill and research on this skill has shown that learners use a variety of strategies to assist them with the acquisition, storage, and retrieval of information.

Strategies can be defined as learning techniques, behaviors, problem-solving or study skills which make learning more effective and efficient (Oxford \& Crookall, 1989; cited in Singhal, 2001). There are different classification systems available for reading strategies but Oxford (1990) offers more useful and comprehensive classification of the various strategies used by learners. According to Oxford (1990), the following six strategies can more appropriately be referred to as subcategories of reading strategies: cognitive strategies that are used by learners to transform or manipulate the language, memory strategies that help learners to remember and retrieve information, compensation strategies that include skills such as inferring, guessing while reading etc., meta-cognitive strategies 
that are behaviors undertaken by the learners to plan, arrange, and evaluate their own learning, affective strategies such as self-encouraging behavior to lower anxiety, and lastly, social strategies that are those techniques that involve other individuals in the learning process and refer to cooperation with peers, questioning, asking for correction, and feedback. These mentioned six strategies can be used to facilitate comprehension (Singhal, 2001).

During the process of reading, sometimes learners use ineffective and inefficient strategies and some factors may influence their use of strategies, such as self-efficacy, motivation, gender, learning style, etc. and of course critical thinking may be one of them.

Critical thinking as one of the factors that affect learning is a cognitive skill which exists and influences the way of our thinking. According to Ennis (2011) critical thinking is the ability to think clearly and rationally. It includes the ability to engage in reflective and independent thinking; the ability to decide what to do or what to believe. Halpern (1999) defines critical thinking as the use of cognitive skills or strategies that increase the probability of a desirable outcome. He argues that critical thinking is purposeful, reasoned, and goal-directed. It is the kind of thinking involved in solving problems, formulating inferences, calculating likelihoods, and making decisions.

Moon (2008) asserts that critical thinking has a significant role in higher education and the professions. It can be considered as a core of higher education and as a fundamental goal of learning. She believes that if critical thinking is clearly expressed in higher education, then students who are achieving those levels of qualification will be critical thinkers.

Concerning the importance of critical thinking in education, Gelder (2005) and Willingham (2007) agree that a primary goal of education is to enable the students to think critically. Akyuz and Samsa (2009) also state that to teach students critical thinking skills is the aim of higher education. They believe that one of the greatest experiences for students in higher education is to think critically and to challenge other students' ideas with those of their own. Thinking skills are crucial for educated persons and by these skills they can cope with a rapidly changing world and deal with reality in a reasonable and independent manner.

\subsection{Statement of the Problem}

Among different factors that may affect the use of reading strategies, the effect of critical thinking was investigated in this study. The problem is the unexplored relationship between critical thinking ability of Iranian EFL learners and their use of reading strategies.

Although critical thinking is almost a new concept in second language education, it is considered as one of the main concerns of researchers in second language acquisition. Researchers (e.g. Halpern, 1999; Gelder, 2005; Willingham, 2007; Akyuz \& Samsa, 2009) believe that critical thinking is one of the main goals of education, so it should receive more attention and all of its possible effects on language learning should be investigated. They indicate that learners who think more critically are more successful in language learning; furthermore, some others (Oxford, 1990; Singhal, 2001; Shang, 2011; Mokhtari \& Sheorey, 2002) believe that successful readers use more effective and a wider range of strategies rather than unsuccessful readers.

There have been some researches that have investigated the relationship between critical thinking and language learning strategies (Nikoopour, Farsani, \& Nasiri, 2011; Fahim, Bagherkazemi, \& Alemi, 2010), but research concerning the relationship between critical thinking and each specific group of strategies (listening, speaking, reading) is limited. So this study is going to investigate the relationship between Iranian EFL learners' critical thinking ability and their use of reading strategies, which are important components of language learning strategies. For this purpose, three major groups of reading strategies will be employed: cognitive, meta-cognitive, and compensatory strategies. The researchers believe the reason for selecting these three groups of strategies is that they are the most important learning strategies resulting in successful reading (see also Shang, 2011).

\subsection{Significance of the Study}

Recently, diversity in reasons for ultimate success and failure among EFL learners provoke language researchers to investigate the different aspects of second or foreign language learning process. Johnson, Archibald and Tenenbaum (2010) state that the ability to read and ultimately learn from reading is a basic skill required for success in any field of study. The acquisition and understanding of the idea from texts require various reading strategies and thinking skills. They believe that critical thinking is one of the essential skills that students should gain for academic success and if students have sufficient critical thinking and meta-cognitive skills, they will perform better in reading comprehension tasks.

Since many researchers and scholars emphasize on the importance of critical thinking as one of the main aims of education and as an aspect that affects language learning, it is important to pay attention to the learners' way of thinking and attempt to enhance critical thinking ability of language learners in our country. 
This study indicates the current level of Iranian EFL learners' critical thinking and those types of reading strategies that they mostly use. It also tries to explore whether EFL learners' critical thinking ability is associated with their use of reading strategies. So the present study can be an aid for educational decision makers to know to what extent Iranian EFL learners have critical mind and if it is related to their language learning. It helps syllabus designers and material developers to create course books that consider critical thinking as one of the effective elements for academic success. It can also notify teachers of the importance of increasing students' critical thinking ability and teaching them how to use this ability to be successful in different processes of learning. In this regard, Halpern (1999) indicates that "there are identifiable critical thinking skills that can be taught and learned, and when students learn these skills and apply them appropriately, they become better thinkers" (p. 70). He also believes that college students should receive explicit instruction in how to think. In the light of this issue, the current study can suggest teachers of reading courses to focus on critical thinking ability of readers while giving priority to two aims in their teaching: making learners prepared to use reading strategies for better reading comprehension and teaching learners critical thinking skills to enhance their ability to think critically.

\subsection{Research Questions}

As mentioned before, the present study tried to identify those categories of reading strategies that are mostly used by Iranian EFL learners and to investigate whether or not a significant relationship exists between Iranian EFL learners' way of thinking and their use of reading strategies. It also aimed to investigate if there is any significant difference between critical thinking ability of male and female learners. Having these purposes in mind, the researchers formulated the following research questions:

1. What categories of Reading Strategies are mostly used by Iranian EFL learners?

2. Is there any significant relationship between the critical thinking ability of Iranian EFL learners and their use of reading strategies?

3. Is there any significant difference between the critical thinking ability of male and female Iranian EFL learners?

\section{Literature Review}

\subsection{Reading Strategies}

Different studies in the area of reading and reading comprehension suggest that learners spontaneously use a variety of reading strategies in the reading process to assist them with the acquisition, storage, and retrieval of information (Zhang, 1993; Singhal, 2001). These strategies reveal how learners manage their interaction with written text, how they conceive a task, what textual cues they attend to, and how they comprehend the text (Singhal, 2001; Maroof \& Yaacob, 2011). Research has discovered that effective EFL/ESL readers use a variety of appropriate strategies (Shang, 2011), on the other hand, literature suggests that appropriate reading strategies may improve reading comprehension (Zhang, 1993). Studies on reading strategies fall into the following categories: identification of different reading strategies employed by successful and unsuccessful language learners, reading strategy instruction, and factors influencing the use of reading strategies (Li \& Wang 2010). However, all studies conducted on reading strategies are consistent in that successful readers tended to use a wider range of strategies and use them more frequently and appropriately than unsuccessful readers (Singhal, 2001).

Shang (2010) investigated the frequency of Taiwanese EFL learners' use of three reading strategies (cognitive, meta-cognitive, compensation strategies), their perceptions of self-efficacy, and the relationships of these two constructs and their English reading performance. He assessed 53 participants' reading comprehension by using the Reading Comprehension section of simulated TOEFL test. The obtained results revealed that the most frequent use of reading strategy was meta-cognitive strategy, followed by compensation strategy, and then followed by cognitive strategy. In addition a significant positive relationship was reported between the use of reading strategies and perceptions of self-efficacy.

$\mathrm{Li}$ and Wang (2010) also aimed to investigate the relationship between reading self-efficacy of Chinese EFL learners and their use of reading strategies. The findings of their study are consistent with Shang's study (2010) because they also found a positive relationship between reading self-efficacy and the use of reading strategies.

In a study, Lien (2011) attempted to investigate EFL learners' reading strategy use in relation to reading anxiety. One hundred and eight EFL freshmen participated in this study and three instruments were administered to them: a questionnaire to investigate the background and reading habits of the participants, the Foreign Language Reading Anxiety Scale to investigate the participants' reading anxiety, and the Survey of Reading Strategies to 
investigate the participants' extensive reading strategies use. A negative correlation was found between reading anxiety and reading strategies. It was also found that the reading strategies employed by learners at high anxiety level were different from those at a low anxiety level. Learners with low anxiety levels tended to use general reading strategies such as guessing, while learners with high anxiety levels employed basic support mechanisms, such as translation, to help them understand texts.

\subsection{Critical Thinking}

Nowadays critical thinking is one of the major concepts under consideration in education and it has also received a significant position in second and foreign language learning (Atkinson, 1997). Several researches have been conducted to investigate the effects of critical thinking on different aspects of second and foreign language learning. Some of them related to this study have been mentioned here.

In the area of critical thinking and language proficiency, Rashid and Hashim (2008) aimed to investigate the relationship between critical thinking and language proficiency. They administered the Cornell Critical Thinking Test (CCTT) and English language proficiency test to 280 undergraduate students of University Utara Malaysia (UUM). The results indicated that there was a significant correlation between critical thinking ability of Malaysian students and their English language proficiency.

Concerning the effects of critical thinking on reading comprehension, Fahim et al. (2010) conducted a study to find if there is any significant relationship between test takers' critical thinking ability and their performance on the reading section of TOEFL. 83 female advanced EFL learners studying English at a private institute in Iran took part in this study. For the purpose of the study, the reading section of PBT (paper-based TOEFL) and the critical thinking appraisal were administered to the participants. The results of the critical thinking appraisal were correlated with the scores on the reading section of Paper-Based TOEFL. The findings indicated a statistically significant advantage for those with greater critical thinking skills. The researchers concluded that critical thinking is very important for answering reading comprehension questions, especially those related to main ideas.

Another study, similar to this area of investigation, was conducted by Kamali and Fahim (2011) to investigate the relationship between critical thinking ability, resilience, and reading comprehension of texts containing unknown vocabulary items. 63 male and female EFL intermediate students were administered a critical thinking questionnaire, a resilience scale, a vocabulary checklist and a validated battery of four reading tests. Results showed that a) the levels of critical thinking had significant effect on the scores of the subjects on resilience scale, b) the levels of critical thinking had significant effect on the subjects' reading ability of texts with unfamiliar vocabulary items, and c) the levels of resilience had significant effect on the subjects' reading ability of texts with unfamiliar vocabulary items. The findings indicating that levels of critical thinking had significant effect on the learners' reading ability are consistent with the findings of the previous study (Fahim et al., 2010) that indicated a significant relationship between critical thinking levels of learners and their scores on the reading section of Paper-Based TOEFL.

Fahim and Komijani (2010) attempted to identify any significant relationship between critical thinking ability, L2 vocabulary knowledge, and L2 vocabulary learning strategies of Iranian EFL learners. The data, collected through a productive vocabulary levels test and a critical thinking questionnaire that were administered to 70 intermediate EFL students, were analyzed and the results revealed that Iranian EFL learners' vocabulary knowledge was significantly related to their critical thinking ability. In addition the participants' critical thinking ability was correlated positively with determination, memorization, cognitive, and meta-cognitive strategies of L2 vocabulary learning but not with social ones.

Moreover, Nikoopour et al. (2011) investigated the relationship between critical thinking and the use of direct and indirect language learning strategies used by Iranian EFL learners. They selected 100 college students majoring in English Translation, and then, two survey instruments, the Strategy Inventory for Language Learning (SILL), and a Questionnaire of Critical Thinking, were administered among them. A statistically significant relationship was found between critical thinking and the use of specific direct and indirect language learning strategies, such as cognitive, meta-cognitive, and social, but not with memory, compensation, and affective strategies.

In the light of the above literature, it can be implied that critical thinking has an effective role on the processes of foreign language learning and learners who are more critical are more successful in language learning.

\section{Method}

\subsection{Participants}

A minimum of 75 Iranian EFL senior students, 35 males and 40 females, majoring in English Literature and 
English Translation at the university of Sistan and Baluchestan (in zahedan, Iran) were selected by the researchers as the participants of this study. Gender was considered as a variable in this study, so its potential influence on the results has been separately taken into consideration.

\subsection{Instruments}

The researchers employed two kinds of instruments to conduct this empirical research, a questionnaire of critical thinking and a questionnaire of reading strategies. The Persian version of a critical thinking questionnaire including 30 multiple choice items was administered to the participants to evaluate the skills of analysis, inference, evaluation, inductive reasoning and deductive reasoning. The critical thinking questionnaire was adopted from Naeini's thesis (2005), which in turn was adapted from Honey (2004). According to Naeini (2005), the English version of critical thinking questionnaire was translated by her to guarantee the full comprehension of the questions by participants. A reading strategy questionnaire adopted from Shang (2010) was employed to measure the frequency of students' self-reported strategy uses. Shang himself adopted this questionnaire from Oxford's (1990) Strategy Inventory for Language Learning (SILL, ESL/EFL version 7.0). This reading strategy questionnaire included 44 items and consisted of three major categories of general use of reading strategies: cognitive (items 1 to 16), meta-cognitive (items 17 to 33), and compensation strategies (items 34 to 44).

\subsection{Data Collection and Analysis}

The Reading Strategy Questionnaire and Critical Thinking Questionnaire were administered to the participants in one session, first the Critical Thinking Questionnaire and then the Reading Strategy Questionnaire. The participants were requested to select the most appropriate answers to the questions. The questionnaire administration took approximately 40 minutes. Having collected the two completed questionnaires, the researchers analyzed the data through using the Statistical Package for Social Sciences (SPSS). The descriptive statistics were calculated primarily to determine what kinds of reading strategies Iranian EFL learners use. Since the research aimed to find out the relationship between critical thinking and reading strategy use, Pearson Product- Moment Correlation was used. A $t$-test was also employed to explore the difference between male and female EFL learners' critical thinking ability.

\section{Results}

\subsection{Research Question 1: What Categories of Reading Strategies Are Mostly Used by Iranian EFL Learners?}

A general look at table 1 shows that the participants used all three types of reading strategies (cognitive, meta-cognitive, and compensation) but differently; however, the extent of using each strategy was different. According to the results, the most frequently used reading strategy was found to be meta-cognitive strategy, followed by cognitive strategy, and then followed by compensation strategy. In other words, the participants used reading strategies in the following order: meta-cognitive (mean=61.88), cognitive (mean=57.28), and compensation strategies (mean=39.11).

Table 1. Descriptive statistics of reading strategies (cognitive, meta-cognitive, and compensation)

\begin{tabular}{lcclcll}
\hline Reading Strategies & $\mathrm{N}$ & Mean & Std. Deviation & Std. Error & Minimum & Maximum \\
\hline Cognitive & 75 & 57.28 & 7.553 & .872 & 28 & 71 \\
Meta-cognitive & 75 & 61.88 & 8.530 & .985 & 34 & 82 \\
Compensation & 75 & 39.11 & 5.610 & .648 & 24 & 51 \\
Total & 225 & 52.76 & 12.263 & .818 & 24 & 82 \\
\hline
\end{tabular}

According to Table 1, the mean score of meta-cognitive strategies are higher than that of other reading strategies (cognitive and compensation); that is, Iranian EFL learners mostly use meta-cognitive strategies to solve their deficiencies in reading comprehension. In order to make the results more tangible they are indicated in bar graphs (Figure 1). 


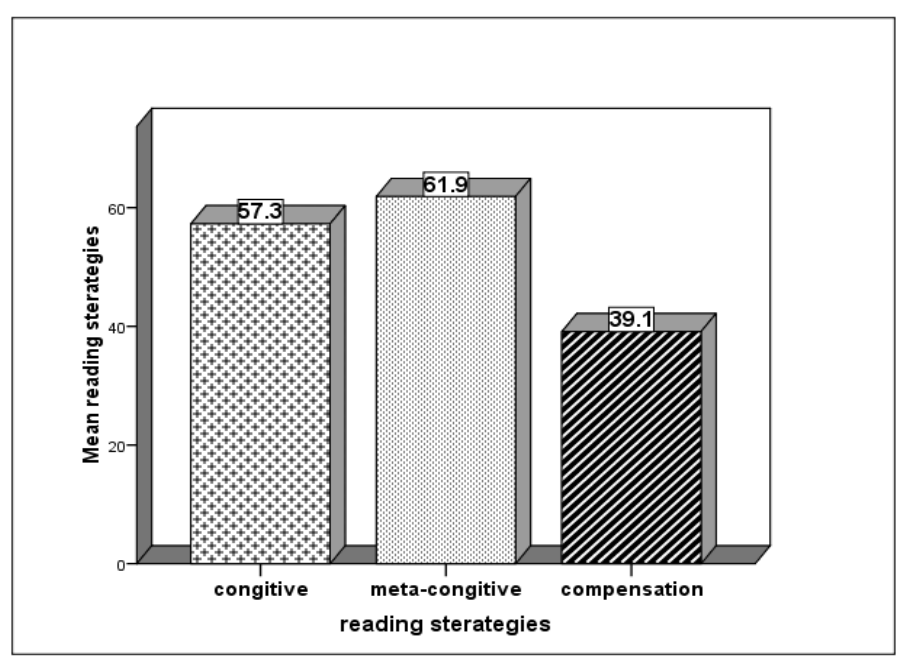

Figure 1. Graph showing the mean scores of three reading strategies

\subsection{Research Question 2: Is There Any Significant Relationship between Critical Thinking Ability of Iranian EFL Learners and Their Use of Reading Strategies?}

To answer to the above research question, Pearson Product-Moment Correlation was used. Here, for calculating Pearson $r$, critical thinking has been considered as an independent variable and reading strategies as dependent variable. As Table 2 shows, by calculating the correlation, the researchers found a significant but low correlation between critical thinking and use of reading strategies. The results indicated that reading strategies were significantly correlated with critical thinking, with the observed value of Pearson $r=0.413$ at the 0.05 level of significance. This small but positive and significant value of Pearson $r$ indicates that learners' critical thinking ability has a positive and significant relationship with their use of reading strategies.

Table 2. Correlation between critical thinking and reading strategies

\begin{tabular}{lll}
\hline & & Critical Thinking \\
\hline \multirow{3}{*}{ Reading Strategies } & Pearson Correlation & $.413^{* *}$ \\
& sig. (2-tailed) & .000 \\
& $\mathrm{~N}$ & 75 \\
\hline
\end{tabular}

**. Correlation is significant at the 0.05 level (2-tailed).

Pearson $r$ was also calculated between critical thinking and each one of the cognitive, meta-cognitive, and compensation strategies separately. Table 3 shows the related results. According to the results, the researchers found a low but significant relationship between critical thinking and each one of the cognitive, meta-cognitive, and compensation strategies.

Table 3. Correlation between critical thinking and cognitive, meta-cognitive, and compensation strategies

\begin{tabular}{llll}
\hline & Cognitive & meta-cognitive & compensation \\
\hline Pearson Correlation & $.344^{* *}$ & $.357^{* *}$ & $.350^{* *}$ \\
Sig. (2-tailed) & .002 & .002 & .002 \\
N & 75 & 75 & 75 \\
\hline
\end{tabular}

**. Correlation is significant at the 0.05 level (2-tailed).

Critical thinking was significantly correlated with cognitive strategies with the observed value of Pearson $r=$ 0.344 , with meta-cognitive strategies with the observed value of Pearson $r=0.357$, and with compensation strategies with the observed value of Pearson $r=0.350$. Although all these values are small but they are 
significant and can prove that level of critical thinking ability is significantly related to the use of cognitive, meta-cognitive, and compensation strategies.

4.3 Research Question 3: Is There Any Significant Difference between Critical Thinking Ability of Male and Female Iranian EFL Learners?

Table 4 shows the descriptive statistics related the mean scores of male and female learners on critical thinking.

Table 4. Descriptive statistics of critical thinking

\begin{tabular}{clc}
\hline Critical thinking & Male & Female \\
\hline $\mathrm{N}$ & 35 & 40 \\
Mean & 102.14 & 95.32 \\
Std. Error of Mean & 2.114 & 2.197 \\
Std. Deviation & 12.504 & 13.898 \\
\hline
\end{tabular}

As Table 4 shows, the mean score of males at critical thinking is 102.14 and the mean score of females is 95.32 . This indicates that male learners are better than females in critical thinking. To make the result more tangible, this difference between two means has been shown in bar graph. Figure 2 shows this.

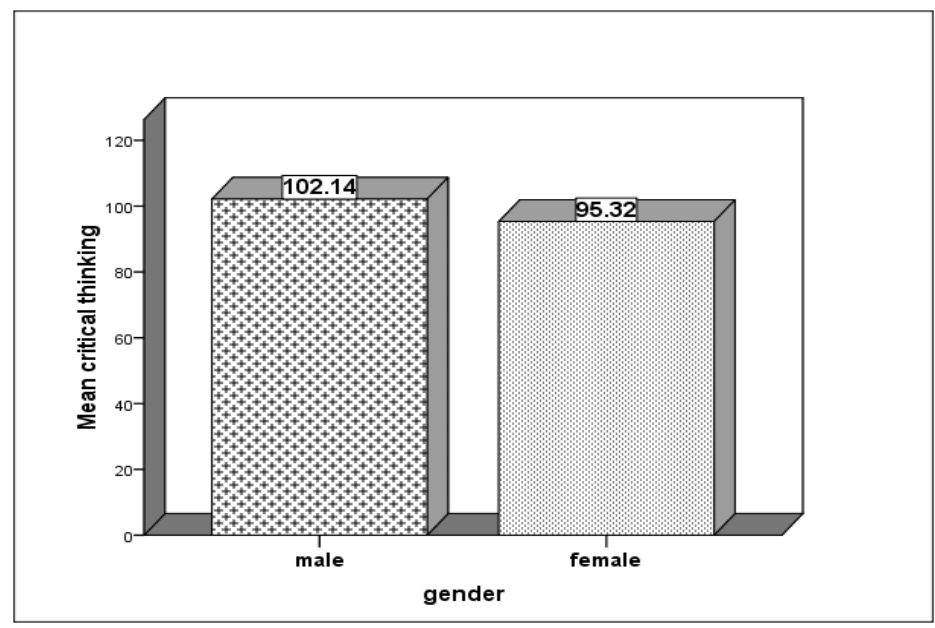

Figure 2. Males' mean score vs. Females' mean score on Critical Thinking

Figure 2 clearly indicates that critical thinking of male learners is to some extent better than that of females. To find out if the difference between critical thinking ability of male and female learners is significant, an independent $t$-test was employed. Table 5 shows the results.

Table 5. Independent Samples $t$-Test: male and female difference on critical thinking

\begin{tabular}{|c|c|c|c|c|c|c|c|c|c|}
\hline & \multicolumn{2}{|c|}{$\begin{array}{l}\text { Levene's Test for } \\
\text { Equality } \\
\text { Variances }\end{array}$} & \multicolumn{5}{|c|}{ t-test for Equality of Means } & \multirow[b]{2}{*}{$\begin{array}{l}95 \% \\
\text { Interval } \\
\text { Difference } \\
\end{array}$} & \multirow[b]{2}{*}{$\begin{array}{l}\text { Confidence } \\
\text { of the } \\
\text { ce }\end{array}$} \\
\hline & & & & & & & $\begin{array}{l}\text { Std. Error } \\
\text { Differenc }\end{array}$ & & \\
\hline & $\mathrm{F}$ & Sig. & $\mathrm{t}$ & $\mathrm{df}$ & (2-tailed) & Difference & & Lower & Upper \\
\hline $\begin{array}{l}\text { Equal variances } \\
\text { assumed }\end{array}$ & .229 & .634 & 2.220 & 73 & .030 & 6.818 & 3.071 & .698 & 12.938 \\
\hline $\begin{array}{l}\text { Equal variances } \\
\text { not assumed }\end{array}$ & & & 2.236 & 72.93 & .028 & 6.818 & 3.049 & .741 & 12.895 \\
\hline
\end{tabular}


As Table 5 shows, the observed $t$-value is 2.236 with its 72 degrees of freedom. The Sig. value has been obtained 0.030 that is lower than $\alpha=0.05$. This indicates that the difference between males' and females' critical thinking is significant. This result indicates that there is a difference between male and female learners in their critical thinking and so it can be concluded that gender can be an influential factor in the ways of thinking.

\section{Discussion}

As mentioned before, descriptive statistics related to the use of reading strategies showed that learners used all three subcategories of reading strategies: cognitive strategies $(\mathrm{M}=57.28, \mathrm{SD}=7.553)$, meta-cognitive strategies $(\mathrm{M}=61.88, \mathrm{SD}=8.530)$, and compensation strategies $(\mathrm{M}=39.11, \mathrm{SD}=5.610)$. By comparing the means of these three reading strategies, it was found that the most frequent use of reading strategies was meta-cognitive, followed by cognitive, and then followed by compensation strategies. As shown in Table 1, the mean values for the strategy use ranged from 39.11 to 61.88 , and the mean score of all three reading strategies was 52.76 . These findings indicate that the overall frequency of reading strategy use was 'usually'; that is, students generally have a clear awareness of the use of the combination of strategies frequently, particularly using meta-cognitive strategies, in order to get a high score in reading. Such results support the findings of Shang (2010) and Li and Wang (2010). Shang (2010) in his study found that Chinese learners used all three reading strategies (cognitive, meta-cognitive, and compensation) in the following order: meta-cognitive strategies followed by compensation strategies, and then followed by cognitive strategies. Li and Wang (2010) reported that learners used all three reading strategies (cognitive, meta-cognitive, and social/affective) in the following order: meta-cognitive strategies, followed by cognitive strategies, and then followed by social/affective strategies. By comparing the results of these two studies and that of the present study, it can be concluded that learners not only use a combination of all reading strategies, but also they use meta-cognitive strategies more frequently than other strategies. Learners frequently use meta-cognitive strategies to manage and evaluate their own learning and also to overcome their deficiency in English reading.

Critical thinking is one of the cognitive abilities that "increases the probability of a desirable outcome,...the kind of thinking involved in solving problems, formulating inferences, calculating likelihoods, and making decisions" (Halpern, 2003, p. 6; cited in Kamali and Fahim, 2011). The findings of the present study seem to confirm the important role of critical thinking in L2 learning. As discussed before, through the analysis of the results, the researchers found a low positive significant relationship between critical thinking and the overall use of reading strategies with the observed value of $r=0.413$ at the 0.05 level of significance (Table 2). Critical thinking was also correlated positively with each one of cognitive $(r=0.344)$, meta-cognitive $(r=0.357)$, and compensation strategies $(r=0.350)$. This indicated that critical thinking ability of Iranian EFL learners affected their use of reading strategies slightly and those who thought more critically used more reading strategies; those who had greater critical thinking ability obtained higher reading strategies score. This result emphasizes the important role of critical thinking in language learning and is in agreement with the findings in the literature (Nikoopour et al., 2011; Kamali \& Fahim, 2011; Fahim \& Komijani, 2010; Rashid \& Hashim, 2008), concluding that it is very important for students who want to be successful in education to have the ability to think critically.

Nikoopour et al. (2011) in their study found a strong relationship between Iranian EFL learners' critical thinking and their use of direct and indirect strategies. They also found that critical thinking was correlated positively with cognitive, meta-cognitive, and social language learning strategies, but not with compensation, memory and affective strategies. So they claimed that a unique change in critical thinking has a large effect on the overall use of direct and indirect language learning strategies. By analyzing the results of their study and the results of the present study, the researchers can claim that critical thinking affects language learning and this also supports the claim of Kamali and Fahim (2011) who reported that EFL learners' critical thinking levels have significant effects on their reading comprehension ability when faced with unknown vocabulary items. According to Kamali and Fahim (2011) improvements in critical thinking are paralleled by improvements in reading comprehension. They believe that the presence of such a strong relationship may be due to the fact that critical thinking and reading are both cognitive abilities which have some identifiable cognitive skills in common.

Similarly, Fahim and Komijani (2010) found a significant relationship between critical thinking, L2 vocabulary knowledge, and L2 vocabulary learning strategies of Iranian EFL learners. They reported that critical thinking ability exists and influences the breadth and depth of EFL learners' vocabulary repertoire. According to Fahim and Komijani (2010), thinking critically and systematically will improve the way learners learn and critical thinking also improves comprehension by helping learners analyze the logical structure of the texts.

The present study is also in agreement with the study of Rashid and Hashim (2008) and supports its findings. Rashid and Hashim (2008) found a moderate significant relationship between Malaysian EFL learners' critical 
thinking ability and their English language proficiency. They concluded that critical thinking ability is positively correlated with proficiency in English, and if learners' critical thinking ability is heightened, their English proficiency will be improved accordingly.

As a whole, the present study and all of the above mentioned studies indicate that critical thinking ability enhances language skills and it is a vital ability for learners in order to perform successfully in language learning.

\section{Conclusion}

The present study was carried out to identify those categories of reading strategies that are mostly used by Iranian EFL learners and to find out if there was any significant correlation between the critical thinking of learners and their use of reading strategies. The difference between critical thinking of males and females was also investigated. Results indicated that among the three subcategories of reading strategies (cognitive, metacognitive, and compensation), the most frequently used category was metacognitive strategies, and the least frequently used one was compensation strategies. A low positive correlation was observed between the two variables at issue. It implies that those with high critical thinking used more reading strategies. In addition, the results showed that critical thinking level of males was higher than that of females. The obtained positive correlation between critical thinking and the use of reading strategies may support the findings of many previous studies that investigated the effectiveness of critical thinking on the language learners' success during the process of foreign language learning. As mentioned in the literature review, there are many other studies that prove the effectiveness of critical thinking on different aspects of second or foreign language learning (Nikoopour et al., 2011; Fahim et al., 2010; Kamali \& Fahim, 2011; Rashid \& Hashim, 2008).

In conclusion, because of the significant role of critical thinking in developing effective language learning, it needs to be promoted among language learners. So, enhancing learners' critical thinking can be considered as one of the language teachers' tasks. This study recommends language teachers to cultivate learners' critical thinking and their awareness of reading strategy use simultaneously because their integration will contribute to better reading comprehension.

\section{References}

Atkinson, D. (1997). A critical approach to critical thinking in TESOL. TESOL Quarterly, 31, 71-89.

Akyuz, H. I., \& Samsa, S. (2009). The effects of blended learning environment on the critical thinking skills of students. Procedia Social and Behavioral Sciences, 1, (2009), 1744-1748.

Chamot, A. (2004). Issues in language learning strategy research and teaching. Electronic Journal of Foreign Language Teaching, 1, 14-26.

Chastain, K. (1988). Developing second language skills: theory and practice ( $3^{\text {rd }}$ ed.). San Diego CA: Harcourt Brace Jovanovich.

Egan, B. D. (2005). The role of critical thinking in effective decision making. Retrieved March 02, 2008, from http://www.Globalknoelede.com

Ennis, R. H. (2011). What is critical thinking. Retrieved January 10, 2011, from http://www.criticalthinking.net/definition.html

Fahim, M., \& Komijani, A. (2010). Critical thinking ability, L2 vocabulary knowledge, and L2 vocabulary learning strategies. Journal of English studies, 1(1), 23-38.

Fahim, M., Bagherkazemi, M., \& Alemi, M. (2010). The relationship between test takers' critical thinking ability and their performance on the reading section of TOEFL. Journal of Language Teaching and Research, 1(6), 830-837. http://dx.doi.org/10.4304/1.6.830=837

Gelder, T. V. (2005). Teaching critical thinking: some lessons from cognitive science. College Teaching, 53(1), 41-48.

Halpern, D. F. (1999). Teaching for critical thinking: Helping college students develop the skills and dispositions of a critical thinker. New Directions for Teaching and Learning, 1999(80), 69-74.

Halpern, D. F. (2003). Thought and Knowledge: An introduction to critical thinking ( $4^{\text {th }}$ ed.). Mahwah, NJ: Lawrence Erlbaum Associates.

Honey, P. (2004). Critical Thinking Questionnaire. Retrieved Feb, 2005, From http://www.PeterHoney.com

Johnson, T. E., Archibald, TH. N., \& Tenebaum, G. (2010). Individual and team annotation effects on students' reading comprehension, critical thinking, and meta-cognitive skills. Computers in Human Behavior, 
26(2010), 1496-1507. http://dx.doi.org/10.1016/05.014

Kamali, Z., \& Fahim, M. (2011). The Relationship between critical thinking ability of Iranian EFL learners and their resilience level facing unfamiliar vocabulary items in reading. Journal of Language Teaching and Research, 2(1), 104-111. http://dx.doi.org/10.4304/2.1.104-111

Li, Y., \& Wang, Ch. (2010). An empirical study of reading self-efficacy and the use of reading strategies in Chinese EFL context. Asian EFL Journal, 12, 144-161.

Lien, H. Y. (2011). EFL learners' reading strategy use in relation to reading anxiety. Language Education in Asia, 2(2), 2011.

Maarof, N., \& Yaacob, R. (2011). Meaning-making in the first and second language: reading strategies of Malaysian students. Procedia Social and Behavioral Sciences, 12(2011), 211-223. http://dx.doi.org/10.1016/02.029

Mokhtari, K., \& Sheorey, R. (2002). Measuring ESL students' awareness of reading strategies. Journal of Developmental Education, 25(3), 2-8.

Moon, J. (2008). Critical thinking: An exploration of theory and practice. UK: Library of Congress.

Naeini, J. (2005). The Effects of Collaborative Learning on Critical Thinking of Iranian EFL Learners. Unpublished Master Thesis, Islamic Azad University of Tehran, Central branch, Iran.

Nikoopour, J., Amini Farsani, M., \& Nasiri, M. (2011). On The relationship between critical thinking and language learning strategies among Iranian EFL learners. Journal of Technology \& Education, 5(3).

Oxford, R. L. (1990). Language learning strategies: What every teacher should know. Boston: Heinle \& Heinle.

Oxford, R., \& Crookall, D. (1989). Research on language learning strategies: Methods, findings, and instructional issues. Modern Language Journal, 73, 404-419.

Rashid, R. A., \& Hashim, R. A. (2008). The Relationship between critical thinking and language proficiency of Malaysian and undergraduates. Proceeding of the EDU-COM 2008 International Conference, Symposia and Campus Events, 19-21 November 2008, Edith Cowan University, Perth Western Australia.

Richards, J. C., \& Renandya, A. W. (2002). Methodology in language teaching: An Anthology of current practice. Cambridge University Press.

Shang, H. F. (2010). Reading strategy use, self-efficacy and EFL reading comprehension. Asian EFL Journal, 12, $18-40$.

Shang, H. F. (2011). Exploring the relationship between EFL proficiency level and reading strategy use. Journal of Language Teaching and Research, 2(1), 18-27.

Singhal, M. (2001). Reading proficiency, reading strategies, metacognitive awareness and L2 readers. The Reading Matrix, 1(1).

Willingham, D. T. (2007). Critical thinking: why is it hard to teach? Arts Education Policy Review, 109(4), 21-29.

Zhang, Z. (1993). Literature review on reading strategy research. Paper presented at the Annual Meeting of the Mid-South Educational Research Association, New Orleans, LA, November 10-12, 1993. 